\title{
Benefits of Cotton Seed Treatments for the Control of Seedling Diseases in Relation to Inoculum Densities of Pythium Species and Rhizoctonia solani
}

\author{
R. M. Davis, Cooperative Extension Specialist, J. J. Nunez, Staff Research Associate, and K. V. Subbarao, Assis- \\ tant Plant Pathologist/Cooperative Extension Specialist, Department of Plant Pathology, University of California, \\ Davis 95616
}

\begin{abstract}
Davis, R. M., Nunez, J. J., and Subbarao, K. V. 1997. Benefits of cotton seed treatments for the control of seedling diseases in relation to inoculum densities of Pythium species and Rhizoctonia solani. Plant Dis. 81:766-768.

Twenty-five field trials conducted over a 3-year period in five San Joaquin Valley counties included the following treatments: nontreated cotton seed; seed treated with myclobutanil for the control of Rhizoctonia solani-induced damping-off; seed treated with metalaxyl for the control of Pythium-induced damping-off; and seed treated with a combination of the two fungicides. The following parameters were measured: soil populations of Pythium spp. and $R$. solani at planting, soil temperature at planting, air temperatures for 5 days after planting, soil particle analysis, EC, calcium, pH, organic matter, and plant stands from each treatment. In 1993 and 1994, myclobutanil and the combination of the two fungicides resulted in improved stands in 15 of 18 fields. Metalaxyl did not increase stands in any field in 1993 to 1994. In 1995, the combination of fungicides increased stands relative to the nontreated seeds and was more effective in increasing stands than myclobutanil or metalaxyl alone. Pythium populations were much greater in 1995 than in 1993 to 1994 and may explain the increase in plant stands with the combination of fungicides and metalaxyl alone. Covariate analysis of the data indicated no relationship between stand increases from fungicide seed treatment and any of the soil parameters measured. Heat units following planting were not limiting and had no effect on stands. Populations of pathogens were not related to benefits of fungicides, with the exception of a negative correlation between stand increases from seed treatment with myclobutanil and Pythium populations. Apparently, seed protected with a fungicide active against $R$. solani were more susceptible to infection by Pythium spp. In general, the fungicide seed treatment active against $R$. solani increased stands of the cultivar Maxxa regardless of soil type and pathogen populations. Increased stands from the metalaxyl treatment occurred in 1 of the 3 years of the study.
\end{abstract}

In California, an estimated 58,491 bales of cotton (Gossypium hirsutum L.) were lost yearly to seedling diseases in 1991 to 1993 (2). To reduce the severity of seedling disease and optimize stand establishment, most seed is treated with fungicide seed dressings for the control of damping-off caused by Pythium spp. and Rhizoctonia solani Kühn anastomosis group (AG)-4 (teleomorph: Thanatephorus cucumeris (A. B. Frank) Donk). The need for control measures has been clearly demonstrated under cool soil temperatures, which favor the development of seedling diseases $(3,4,10)$. The benefits of cotton seed fungicides are less clear, however, in fields where inoculum densities of soilborne pathogens are relatively low or where soil factors promote rapid seedling emergence and growth. The goal of this project was to predict, if possible, the benefits of specific

Corresponding author: R. M. Davis

E-mail: rmdavis@ucdavis.edu

Accepted for publication 27 March 1997.

Publication no. D-1997-0519-07R

(C) 1997 The American Phytopathological Society fungicide seed treatments on cotton stand establishment in the San Joaquin Valley of California relative to inoculum densities of $R$. solani and Pythium spp., fungicide seed treatments, soil and air temperatures, and various soil parameters. A second objective was to determine population thresholds of Pythium spp. and $R$. solani that result in stand losses for the cultivar Maxxa, the dominant cultivar in use in California today.

\section{MATERIALS AND METHODS}

Acid-delinted cotton seed (cultivar Maxxa) was coated with fungicides in a Hege Seed Treater (Hege Equipment Inc., Colwich, KS) as follows (i) none, (ii) myclobutanil (NuFlow M, Wilbur-Ellis Co., Fresno, CA) at $39.1 \mathrm{mg}$ a.i./100 $\mathrm{g}$ seed for the selective control of damping-off caused by $R$. solani, (iii) metalaxyl (Apron FL, Gustafson Inc., Plano, TX) at $18.5 \mathrm{mg}$ a.i./100 $\mathrm{g}$ seed for the selective control of Pythium spp., and (iv) myclobutanil + metalaxyl. The fungicides were added to water for a final volume of $1.8 \mathrm{ml}$ per 100 $\mathrm{g}$ of seed, which included an additional $10 \%$ of product to account for loss on the container during treatment. One hundred twenty seeds were planted in each $7.6 \mathrm{~m}$, single-row plot. Treatments were replicated 4 to 8 times in a randomized complete block design. Experiments were established in 25 locations in five San Joaquin Valley counties in April to May, 1993 to 1995 . When possible, seed from each treatment was planted an equal number of times through each planter unit (John Deere 71 FlexPlanters fitted with Kincaid cones, Kincaid Equipment Manufacturers, Haven, KS) at each site to eliminate variation attributable to differences in planting depth. At planting, soil temperature at approximately 10:00 a.m. at a depth of $10 \mathrm{~cm}$ was measured and $2.5-\mathrm{cm}$-diameter soil samples (surface to $15 \mathrm{~cm}$ deep) were collected from 10 sites within each block and pooled.

Inoculum densities of fast-growing $P y$ thium spp. (primarily $P$. ultimum and $P$. irregulare) were determined by soil dilution and plating on a selective medium containing pimaricin, pentachloronitrobenzene, ampicillin, penicillin, and rifampicin (7). Identification of Pythium spp. was made from morphological characteristics of cultures on potato-carrot agar and on blades of sterilized grass in water (12). Inoculum densities of $R$. solani were determined in $150 \mathrm{~g}$ subsamples by plating the organic matter fraction onto water agar (13). The moisture content of each soil sample was determined gravimetrically. Soil samples from each location were then bulked and analyzed by the Soil, Water, and Plant Analysis Laboratory, Cooperative Extension, University of California, Davis, for $\mathrm{pH}$, electrical conductivity, organic matter, exchangeable calcium, phosphorus concentration, and particle size distribution.

Approximately 3 weeks after planting, the number of surviving seedlings in each plot was determined. At that time, about 15 seedlings were gently lifted from each plot sown with nontreated seed. In the laboratory, the seedlings were washed in water, surface-disinfested for $1 \mathrm{~min}$ in a $0.5 \%$ solution of sodium hypochlorite, and plated on water agar to isolate fungi.

Plant stand data from each location and treatment were transformed to normalize the data using the logit transformation (logit $X=\log _{\mathrm{e}}$ (stand $) /(120$ - stand), where $X$ is the transformed stand value). Since the locations were not common for each year of the study, analysis of variance was conducted separately by year to de- 
termine treatment differences. Treatment means were compared using Duncan's Multiple Range Test $(P=0.05)$. Covariate analysis to determine the potential relationship between plant stands and candidate covariates such as pathogen populations, air and soil temperatures, and soil factors was conducted. Residuals were plotted against individual covariates to determine associations. The analysis of possible synergism between the two fungicides was determined by the method of Abbott (1). Briefly, the expected efficacy of the combination treatment, expressed as percent control, was calculated as $\% C_{\exp }=A+B-$ $(A B / 100)$, in which $A$ and $B$ were the control levels contributed by each fungicide. If the ratio between the experimentally observed efficacy of the combination $\left(C_{\text {obs }}\right)$ and the expected efficacy of the combination $\left(C_{\text {exp }}\right)$ was greater than 1 , the effects of the two fungicides were determined to be synergistic; otherwise, the effects were considered to be additive. All analyses were conducted in SAS (release 6.11, SAS Institute, Inc., Cary, NC).

\section{RESULTS AND DISCUSSION}

Analysis of variance indicated that the fungicide treatments generally had a significant effect on cotton plant stands (Table 1). Except for three trials, where no significant differences occurred among treatments (these data were omitted from the pooled analyses for clarification of general effects by the fungicides), the results were consistent across all locations as indicated by the lack of significant location $\times$ treatment interaction. The myclobutanil seed treatment resulted in stand increases in 22 of the 25 trials (Table 2). The metalaxyl seed treatment did not improve stands in any of the 18 trials in 1993 and 1994, but increased the number of surviving seedlings in 1995 relative to the nontreated control. In 1995, all three treatments improved plant stands compared to the nontreated seed. The combination of the fungicides was more effective in increasing stands than either fungicide alone. The populations of Pythium spp. recovered in the soil samples were considerably greater in 1995 than in 1993 to 1994 (295.3 CFU/g and $31.8 \mathrm{CFU} / \mathrm{g}$, respectively), and may explain the small but significant increases in stands due to metalaxyl in 1995. The increased level of control with the combination of the fungicides was the result of an additive effect of the two materials, and not a result of synergism, as determined by the Abbott procedure (1).

Benefits of the fungicide seed treatments could not be predicted based on any soil parameter or combination of parameters (means across all locations are presented in Table 3). Although $R$. solani was isolated from $60 \%$ of diseased cotton seedlings (whereas Pythium spp. were isolated from $15 \%$ of the diseased seedlings), stands were not related to $R$. solani soil populations. Stands were improved with the myclobutanil seed treatment at low and high populations of $R$. solani. A low detection threshold, occurrence of different AG groups within the same site, and other variables may contribute to the lack of a close relationship between native inoculum densities of $R$. solani and disease incidence. A lack of such a relationship was previously reported in radish seedlings (6). There was, however, a significant negative correlation between Pythium populations and stand increases from the myclobutanil seed treatment (Table 4). Apparently, cotton seedlings protected with a fungicide with specific activity against Rhizoctonia (i.e., myclobutanil) are more susceptible to infection by Pythium. This phenomenon was reported in cotton trials in Egypt, where untreated seeds resulted in greater plant stands than seeds treated with a fungicide active against $R$. solani (9). These tive against $R$. solani increased infection by other pathogenic soilborne microorganthe combined fungicides in this study in 1995. Fungicides with varying spectra of activity may provide the greatest benefit, researchers speculated that fungicides acisms. This may also explain the benefit of

since protecting seed and seedlings against infection by one pathogen may increase the incidence or severity of disease caused by the other. The lack of correlation between stands and natural inoculum densities of Pythium spp. is inconsistent with earlier research in the San Joaquin Valley of California where seedling (cultivar SJ-2) survival was directly related to numbers of propagules of Pythium in the soil (5). Differences in susceptibility between cultivars and different temperatures at and soon after planting may account for the varying results.

Degree days (daily high air temperature + daily low air temperature $/ 2-15.5^{\circ} \mathrm{C}$ ) for 5 days following planting in these trials were generally adequate for cotton seed germination and seedling emergence (means of $16.7,40.5$, and $29.8^{\circ} \mathrm{C}$ for 5 days after planting in 1993, 1994, and 1995). Fifteen degree days is considered adequate for seed germination (11). Soil temperatures also were adequate for seed germina-

Table 3. Means, corresponding standard errors of the mean (SE), and ranges for soil parameters in the 25 fields planted in 1993 to 1995

\begin{tabular}{lrr}
\hline Covariate & Mean \pm SE & \multicolumn{1}{c}{ Range } \\
\hline $\mathrm{pH}$ & $7.3 \pm 1.9$ & $6.7-7.7$ \\
$\mathrm{EC}(\mathrm{mS} / \mathrm{cm})$ & $1.3 \pm 0.30$ & $0.48-3.36$ \\
$\mathrm{P} \mathrm{ppm}$ & $28.0 \pm 0.05$ & $10-106$ \\
$\mathrm{X}-\mathrm{Ca}(\mathrm{meq} / 100 \mathrm{~g})$ & $15.9 \pm 1.5$ & $3.6-26.4$ \\
OM \% & $1.3 \pm 0.56$ & $0.45-3.07$ \\
Sand \% & $47.6 \pm 0.1$ & $17-76$ \\
Silt \% & $36.1 \pm 1.4$ & $17-49$ \\
Clay \% & $16.3 \pm 0.8$ & $1-35$ \\
Pythium spp. & & \\
(CFU/g) & $126.7 \pm 12.8$ & $0-725.6$ \\
R. solani & & \\
(CFU/100 g) & $1.4 \pm 0.13$ & $0-7.6$ \\
\hline
\end{tabular}

Table 2. Effect of fungicide seed treatments on cotton (cultivar Maxxa) stand establishment in 22 fields in the San Joaquin Valley of California in 1993 to 1995

\begin{tabular}{lccc}
\hline & \multicolumn{3}{c}{ Number of healthy seedlings/120 seeds } \\
\cline { 2 - 4 } Treatment $^{\mathbf{x}}$ & $\mathbf{1 9 9 3 ( 3 ) ^ { \mathbf { y } }}$ & $\mathbf{1 9 9 4}(\mathbf{1 2})$ & $\mathbf{1 9 9 5}(\mathbf{7})$ \\
\hline None & $68.9 \mathrm{a}^{\mathrm{z}}$ & $73.2 \mathrm{a}$ & $66.2 \mathrm{c}$ \\
Myclobutanil & $90.2 \mathrm{~b}$ & $90.9 \mathrm{~b}$ & $70.9 \mathrm{~b}$ \\
Metalaxyl & $69.2 \mathrm{a}$ & $75.6 \mathrm{a}$ & $69.9 \mathrm{~b}$ \\
Myclobutanil + metalaxyl & $87.0 \mathrm{~b}$ & $92.5 \mathrm{~b}$ & $79.4 \mathrm{a}$ \\
\hline
\end{tabular}

${ }^{\mathrm{x}}$ Myclobutanil and metalaxyl were applied at 39.1 and $18.5 \mathrm{mg}$ a.i./100 g seed, respectively.

${ }^{\mathrm{y}}$ Number of trials. Data from three locations were excluded since there were no differences among treatments.

${ }^{\mathrm{z}}$ Means in each column followed by the same letter are not significantly $(P=0.05)$ different according to Duncan's Multiple Range Test (four to eight replications of 120 seeds per experimental site)

Table 1. Analysis of variance of plant stands influenced by different fungicide treatments at several locations during 1993 to $1995^{z}$

\begin{tabular}{|c|c|c|c|c|c|c|c|c|c|}
\hline \multirow[b]{2}{*}{ Source of variation } & \multicolumn{3}{|c|}{1993} & \multicolumn{3}{|c|}{1994} & \multicolumn{3}{|c|}{1995} \\
\hline & df & MS & $P>F$ & df & MS & $P>F$ & df & MS & $P>F$ \\
\hline Location (loc) & 2 & 1.86 & 0.001 & 11 & 3.49 & 0.001 & 6 & 6.35 & 0.001 \\
\hline $\operatorname{Rep}(\mathrm{loc})$ error $_{\mathrm{a}}$ & 15 & 0.25 & $\ldots$ & 60 & 0.26 & $\ldots$ & 49 & 0.11 & 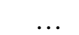 \\
\hline Treatment & 3 & 3.89 & 0.001 & 3 & 13.09 & 0.001 & 3 & 4.32 & 0.001 \\
\hline Loc $\times$ treatment & 6 & 0.05 & 0.945 & 33 & 0.18 & 0.178 & 18 & 0.20 & 0.077 \\
\hline Error $_{b}$ & 45 & 0.17 & $\ldots$ & 180 & 0.14 & $\ldots$ & 147 & 0.13 & $\ldots$ \\
\hline
\end{tabular}

z The logit transformation (logit $X=\log _{\mathrm{e}}$ [stand]/[120 - stand], where $X$ is the transformed stand value) was applied to normalize the data. Data from three locations were excluded since there were no differences among treatments. 
Table 4. Correlations between cotton stand increases ${ }^{\mathrm{x}}$ and soil populations of Pythium spp. (CFU/g soil) or Rhizoctonia solani (CFU /100 g soil)

\begin{tabular}{lrc}
\hline & \multicolumn{1}{c}{$\boldsymbol{r}^{\mathbf{y}}$} & $\boldsymbol{P}>\boldsymbol{R}^{\mathbf{z}}$ \\
\hline Pythium pop. vs. stand increase with myclobutanil treated seed & -0.323 & 0.0001 \\
Rhizoctonia pop. vs. stand increase with myclobutanil treated seed & -0.035 & 0.65 \\
Pythium pop. vs. stand increase with metalaxyl treated seed & 0.047 & 0.54 \\
Rhizoctonia pop. vs. stand increase with metalaxyl treated seed & 0.005 & 0.94 \\
Pythium pop. vs. stand increase with both fungicides on seed & -0.063 & 0.42 \\
Rhizoctonia pop. vs. stand increase with both fungicides on seed & 0.003 & 0.96 \\
\hline
\end{tabular}

x Stand increases are the logit transformed proportion of stand increases relative to the maximum stands observed.

y Pearson's correlation coefficient.

${ }^{\mathrm{z}}$ Probabilities associated with the significance of correlation under the null hypothesis $R=0$.

tion (means of $19.7,22.2$, and $21.0^{\circ} \mathrm{C}$ for 1993, 1994, and 1995, respectively). Soil temperatures of $14.4^{\circ} \mathrm{C}$ or greater are considered adequate for cotton seed germination (8). Thus, temperatures were generally warm and promoted good seedling growth. Although seedling diseases are most prevalent in cool, wet soils, $R$. solani, which has few temperature requirements, consistently reduced cotton stands in this study regardless of temperature. Stand losses due to Pythium spp., which are generally favored by cool temperatures, occurred less frequently, which may reflect the relatively warm temperatures during stand establishment in all 3 years of this study.

In general, the myclobutanil seed treatment resulted in stand improvements regardless of soil type or magnitude of pathogen population, while there was little benefit from the metalaxyl seed treatment directed against infection by Pythium spp. However, both fungicides were required for maximum stands when high Pythium population densities occurred. Further- more, there was an increased level of control with the combination of fungicides in all trials in 1995. Overall, the benefits of seed treatment occurred in almost all sites, which represented a range of soil types, soil and air temperatures, and in soils infested with high or low (undetectable) levels of infestation of Pythium spp. or $R$. solani. Because of the consistent positive results from fungicide seed dressings directed against $R$. solani, a predictive model of the benefits of seed treatments in cottonproducing fields in California could not be established. The relatively low cost of seed treatment, unpredictability of weather, and lack of population thresholds of soilborne pathogens further justify the cost of measures to control seedling diseases of cotton in California.

\section{LITERATURE CITED}

1. Abbott, W. S. 1925. A method of computing the effectiveness of an insecticide. J. Econ. Entomol. 18:265-267.

2. Blasingame, D. 1992-4. Cotton disease loss estimate. Pages 165, 172, and 224 in: Proc. Beltwide Cotton Prod. Conf. National Cotton
Council of America, Memphis, TN

3. Brown, E. A., and McCarter, S. M. 1976. Effect of a seedling disease caused by $R h i$ zoctonia solani on subsequent growth and yield of cotton. Phytopathology 66:111115.

4. Colyer, P. D., Micinski, S., and Nguyen, K. T. 1991. Effect of planting date on the efficacy of an in-furrow pesticide and the development of cotton seedling disease. Plant Dis. 75:739 742 .

5. DeVay, J. E., Garber, R. H., and Matheron, D. 1982. Role of Pythium species in the seedling disease complex of cotton in California. Plant Dis. 66:151-154.

6. Kinsbursky, R. S., and Weinhold, A. R. 1988 Influence of soil on inoculum density-disease relationships of Rhizoctonia solani. Phytopathology 78:127-130.

7. Liddell, C. M., Davis, R. M., Nunez, J. J., and Guerard, J. P. 1989. Association of Pythium spp. with carrot root dieback in the San Joaquin Valley of California. Plant Dis. 73:246-249.

8. McCarter, S. M., and Roncadori, R. W. 1971. Influence of low temperature during cottonseed germination on growth and disease susceptibility. Phytopathology 61:1426-1429.

9. Moustafa-Mahmoud, S. M., Sumner, D. R., Ragab, M. M., and Ragab, M. M. 1993. Interaction of fungicides, herbicides, and planting date with seedling disease of cotton caused by Rhizoctonia solani. Plant Dis. 77:79-86.

10. Roncadori, R. W., and McCarter, S. M. 1972. Effect of soil treatment, soil temperature, and plant age on Pythium root rot of cotton. Phytopathology 62:373-376.

11. Rude, P. A. 1984. Integrated Pest Management for Cotton in the Western Region of the United States. University of California Press, Oakland.

12. van der Platts-Niterink, A. J. 1981. Monograph of the genus Pythium. Stud. Mycol. 21:1-242.

13. Weinhold, A. R. 1977. Population of Rhizoc tonia solani in agricultural soils determined by a screening procedure. Phytopathology 67:566-569. 